\section{Vigabatrin-associated visual field defects in children}

\begin{abstract}
Purpose Vigabatrin (Sabril), a drug that blocks GABA transaminase, has been used in the treatment of epilepsy since 1989. There have been reports of irreversible constriction of the visual field in adult patients related to vigabatrin (VGB) therapy, resulting in reduced VGB usage in adults. Although used as a second or third line agent in adults, in children it is often considered as a first line treatment for several subgroups of seizures in spite of there being no way, in the majority of cases, to monitor visual fields. Some of these children have a pre-existing visual field defect as part of their primary disorder. We aimed to identify whether visual field loss due to VGB was occurring in our hospital.

Methods We have studied the results of ophthalmic examination in 14 children on VGB at Great Ormond Street Hospital who were able to perform Goldmann visual fields. Results Ten of the 14 patients had constriction of their visual fields attributed to VGB. In addition there were 2 patients with suspicious visual field defects thought to be due to VGB. There was pre-existing visual pathway damage in 4 cases and in 2 of these optic disc pallor increased in association with constricted visual fields. However, the optic discs were normal in 7 patients in spite of visual field constriction. Visual acuity was generally normal in spite of gross visual field constriction.

Conclusions We believe that VGB should be used with great caution where there is preexisting visual pathway damage. In other cases the benefits should be considered in relation to the risks, which include irreversible visual field damage. At present visual fields can only be monitored by perimetry, which is often not possible in children with epilepsy.
\end{abstract}

\section{Key words Child, Vigabatrin, Visual fields}

Vigabatrin (gamma-vinyl GABA) enhances gamma-aminobutyrate (GABA)-mediated inhibition of the brain and is used in the treatment of seizures. Vigabatrin (VGB) and another antiepileptic drug, tiagabine (TGB), enhance cerebrospinal levels of GABA. VGB has
I.M. RUSSELL-EGGITT, D.A. MACKEY, D.S.I. TAYLOR, C. TIMMS, J.W. WALKER an intracellular mode of action inhibiting the enzyme GABA transaminase, thereby stopping GABA breakdown within the nerve cell. ${ }^{1,2}$ TGB has an extracellular mode of action inhibiting re-uptake of GABA into neuronal and glial cells. ${ }^{3}$ VGB was first manufactured in 1977 and licensed for use in the UK in 1989 (Sabril). Licensing was rejected in the USA because of neurotoxicity in animals. ${ }^{4}$ Clinical experience with VGB has accumulated mainly in Europe, where the drug has been licensed in several countries since 1989. In 1990 the manufacturers, Hoechst Marion Roussel (HMR), first had reports of visual field constriction in patients receiving VGB. ${ }^{5}$ In 1992, in the medical literature, VGB was felt to be an exciting new treatment for epilepsy without serious side effects. ${ }^{6}$ The first report in the medical literature of VGB-associated visual field loss was in Italian. ${ }^{7}$ It was January 1997 before severe visual field constriction in 3 adults receiving VGB was reported in the British Medical Journal. ${ }^{8}$ By December 1996, 9 cases had been reported to the Committee on Safety of Medicines in UK (CSM UK) and the manufacturers had received 28 reports of visual field loss world-wide of the 140000 patients treated with VGB. ${ }^{9}$ A few months later, in June 1997, there were 95 cases known to the company. ${ }^{10}$ There are 56 cases reported in the medical literature, all but one case in adults, ${ }^{8,10-21}$ and by July 199981 cases reported to the CSM UK. Most reports concentrate on severe visual field loss. HMR currently quotes a prevalence of visual field defects in adults receiving VGB of about 30\% (company communication). A recent study reports a prevalence of $29 \%$ in a survey of 41 patients. ${ }^{21}$ The results of a recent general practitioner questionnaire suggest an incidence of VGB-associated visual field defects of less than $1 \%$, but there was no systematic examination of visual fields. ${ }^{22}$ It is likely that there is a prevalence of more than $30 \%$ for patients on therapy for more than a year, of less severe, but significant visual field loss which is progressive whilst therapy is continued. Once the visual field defect is detected the majority of patients stop VGB. However, there are a few cases where the visual field seems to have stabilised with a reduced dosage. ${ }^{14}$ There are only two reports of improvement in the visual
Received: 7 September 1999 Accepted in revised form 9 December 1999 
field once VGB is stopped, one in a child. ${ }^{18,20}$ All other reports note stabilisation of the visual field once VGB is stopped in spite of several years follow-up. The reports of side effects in adults have severely curtailed the use of VGB. However, VGB continues to be used in children, the majority of whom are unable to perform perimetry tests. There is one case report of VGB-associated visual field loss in a child, a girl aged 10 years. ${ }^{20}$ In this case the visual field loss appeared to reverse after VGB was discontinued. A partial reversibility has been reported in only one adult case. ${ }^{18}$ It has been proposed that lack of reports of visual field defects in children is due to a different GABA transaminase pathway direction in young subjects. ${ }^{23}$ However, the lack of reports of visual field defects in children is more likely due to late detection and under-reporting. We aimed to investigate this possibility in the minority of our patients able to cooperate with Goldmann visual field testing.

Visual field damage may be a drug class effect, but there are only two reports of visual field constriction in the related dugs $\mathrm{TGB}^{24}$ and progabide. ${ }^{25}$ However, there have been no reports of visual field loss in association with TGB therapy reported to the CSM UK. The manufacturers of TGB, Sanofi Winthrop, have no reports of permanent visual impairment from clinical trials and will publish the results shortly on a prospective study of visual fields in patients receiving VGB monotherapy and in combination with other drugs (company communication). A recent study, which included Goldmann perimetry, on 15 patients with a mean duration of TGB therapy of 2.5 years did not show any concentric visual field constriction. ${ }^{26}$

\section{Subjects and methods}

We performed a retrospective notes review of patients receiving VGB who were able to perform Goldmann visual fields at some stage during their therapy. There were 14 patients ( 8 females and 6 males). The age range at the start of VGB therapy was 5 years to 15 years 8 months (average 9 years 10 months). The most frequently used target was I4e and therefore we have compared this isopter where possible in the horizontal meridian in the nasal and temporal field, or noted where a larger target had to be used.

\section{Results (Table 1) \\ Case 1}

A 14-year-old male with complex partial seizures from 5 months of age. VGB was added to carbamazepine (CBZ) at 8 years of age. At 13 years Goldmann and Oculus perimetry both showed constricted visual fields and VGB was stopped. He detected I4e at $40^{\circ}$ and $30^{\circ}$ nasally right and left respectively and temporally $60^{\circ}$ and $55^{\circ}$. With the larger IV4e he achieved $50^{\circ}$ and $45^{\circ}$ nasally and $65^{\circ}$ and $60^{\circ}$ temporally. His visual acuity was $6 / 6$ and his optic discs normal.

\section{Case 2}

A 16-year-old female with developmental delay and onset of seizures at 4 years of age. VGB was added to sodium valproate at 7 years of age. Her visual acuity was $6 / 9$ and her optic discs normal, but she was unable to perform perimetry until 8 years later. At that time her optic discs were still normal and her acuity 6/6.

However, her Goldmann visual field was constricted to $15^{\circ}$ and $20^{\circ}$ nasally and $20^{\circ}$ and $40^{\circ}$ temporally for I4e and $20^{\circ}$ and $25^{\circ}$ nasally and $40^{\circ}$ and $50^{\circ}$ temporally for IV4e

Table 1. Goldmann perimetry results: detection in degrees from fixation in horizontal meridian

\begin{tabular}{|c|c|c|c|c|c|c|}
\hline Case no. & Target size & Right nasal & Left nasal & Right temporal & Left temporal & Duration of VGB \\
\hline 1 & $\mathrm{I} 4 \mathrm{e}$ & 40 & 30 & 60 & 55 & 5 years \\
\hline 2 & $\mathrm{I} 4 \mathrm{e}$ & 15 & 20 & 20 & 40 & 8 years \\
\hline 3 & $\mathrm{I} 4 \mathrm{e}$ & 50 & 50 & 80 & 80 & 1 year 1 month \\
\hline 3 & $\mathrm{I} 4 \mathrm{e}$ & 45 & 45 & 70 & 70 & 2 years 5 months \\
\hline $4^{a}$ & $\mathrm{I} 4 \mathrm{e}$ & - & 20 & 30 & - & 3 years \\
\hline 5 & $\mathrm{I} 4 \mathrm{e}$ & 40 & 40 & 60 & 60 & 7 years \\
\hline 5 & $\mathrm{I} 4 \mathrm{e}$ & 30 & 35 & 50 & 55 & 7 years 5 months \\
\hline $6^{a}$ & $\mathrm{I} 4 \mathrm{e}$ & - & 30 & 45 & - & 3 years \\
\hline $6^{a}$ & IV4e & - & 20 & 40 & - & 3 years 7 months \\
\hline $6^{a}$ & $\mathrm{~V} 4 \mathrm{e}$ & - & 10 & 20 & - & 7 years \\
\hline 7 & $\mathrm{I} 4 \mathrm{e}$ & 30 & 40 & 40 & 55 & 8 years 2 months \\
\hline 7 & $\mathrm{I} 4 \mathrm{e}$ & 35 & 40 & 40 & 50 & 8 years 9 months \\
\hline $8^{\mathrm{b}}$ & $\mathrm{I} 4 \mathrm{e}$ & 50 & 50 & 75 & 70 & 2 months \\
\hline 9 & $\mathrm{I} 4 \mathrm{e}$ & 35 & 40 & 55 & 50 & 2 years 5 months \\
\hline 10 & $\mathrm{I} 4 \mathrm{e}$ & 30 & 30 & 60 & 55 & 1 year 10 months \\
\hline 11 & $\mathrm{I} 4 \mathrm{e}$ & 30 & 30 & 40 & 50 & 3 years 2 months \\
\hline 12 & $\mathrm{I} 4 \mathrm{e}$ & 50 & 50 & 75 & 75 & 2 years 7 months \\
\hline 13 & $\mathrm{I} 4 \mathrm{e}$ & 25 & 30 & 70 & 60 & 1 year 6 months \\
\hline 14 & $\mathrm{I} 4 \mathrm{e}$ & 40 & 40 & 50 & 50 & 11 months \\
\hline 14 & $\mathrm{I} 4 \mathrm{e}$ & 25 & 30 & 30 & 35 & 3 years 6 months \\
\hline Normal & $I 4 e$ & 50 & 50 & 80 & 80 & None \\
\hline
\end{tabular}

${ }^{\mathrm{a}}$ Hemianopia; ${ }^{\mathrm{b}}$ increased blind spot. 

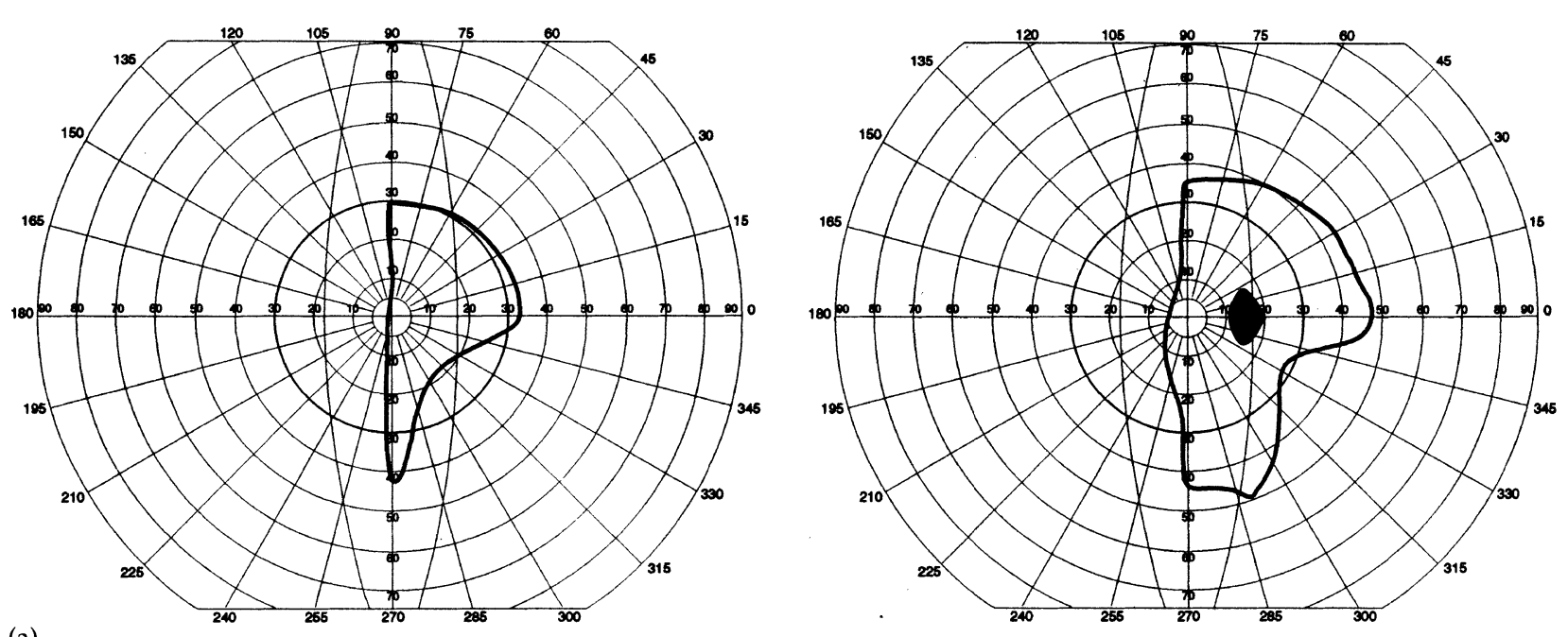

(a)
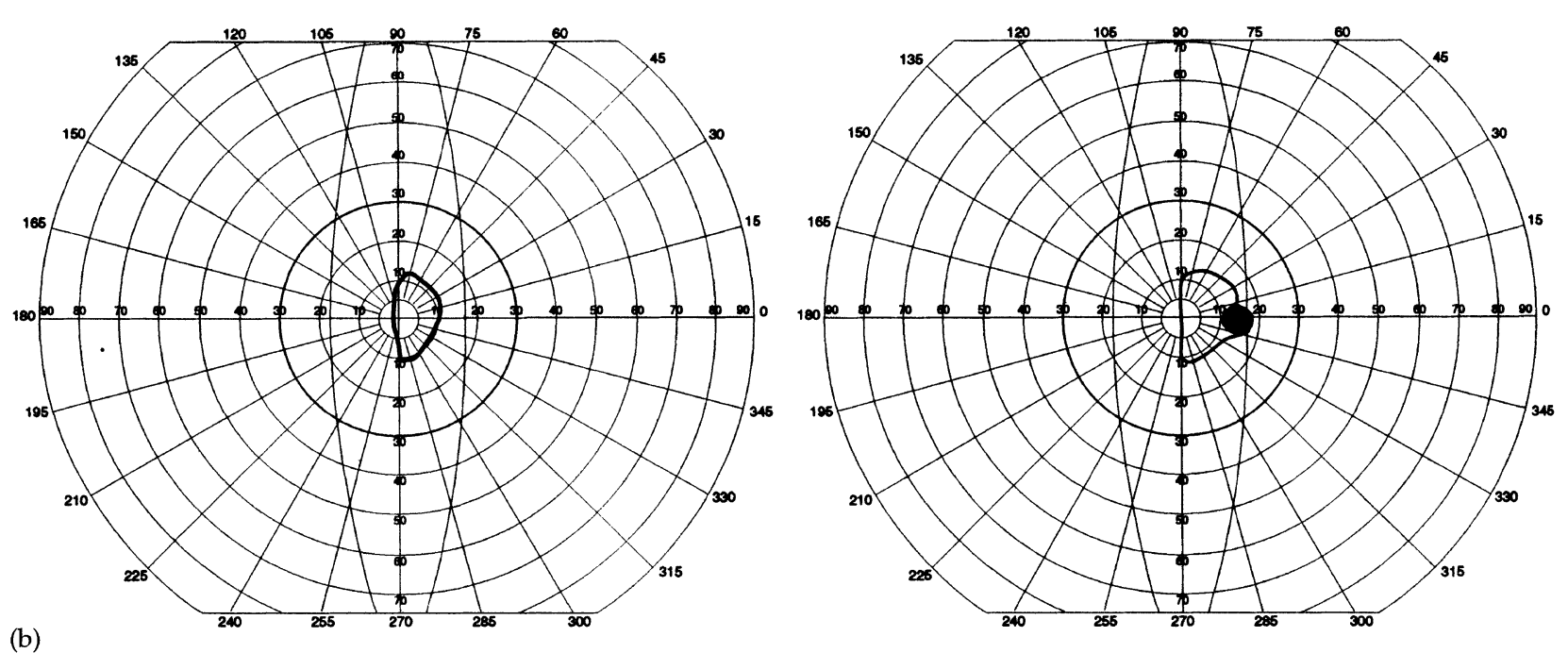

Fig. 1. Case 6. (a) Goldmann perimetry to target I4e performed when the patient complained of constricted visual fields 2 years after resection of a fronto-temporal lesion and 3 years after starting VGB. (b) Goldmann perimetry to the largest target V4e performed 3 years after stopping VGB (with 7 years of VGB therapy in total). Her visual fields have not changed significantly since stopping treatment.

for the right and left eyes respectively. VGB was withdrawn over 9 months. Six months after stopping VGB her visual field has not changed significantly.

\section{Case 3}

An 11-year-old male, with a family history of seizures, with onset of seizures 29 months ago when VGB monotherapy was started. His Goldmann visual fields were normal with detection of $I 4 \mathrm{e}$ at $50^{\circ}$ nasally and $80^{\circ}$ temporally for each eye 13 months after starting VGB. He now detects $I 4 \mathrm{e}$ at $45^{\circ}$ nasally and $70^{\circ}$ temporally, which is not felt to be a significant change, and his visual field is being closely monitored. His acuity is $6 / 4$. His optic discs are not pale, but have 0.6 cups and normal intraocular pressure. This is thought to be physiological cupping.

\section{Case 4}

A 16-year-old female with neurofibromatosis type 1 with developmental delay, perinatal intraventricular haemorrhage, double hemiplegia, cerebral palsy and temporal lobe seizures. VGB was added to CBZ 35 months ago prior to a temporal lobe surgical resection.
Goldmann visual fields confirmed a left homonymous hemianopia and constriction of the visual field 8 months ago and a visual acuity of $6 / 12$ in each eye. Target I4e was detected at $30^{\circ}$ temporally in the right eye and $20^{\circ}$ nasally in the left eye. With target III4e the left nasal field improved slightly to $30^{\circ}$. It was not possible to perform perimetry prior to this.

\section{Case 5}

A 15-year-old female with tuberous sclerosis and onset of seizures at 9 months of age. At 9 years of age VGB was added to CBZ. Goldmann visual fields were first performed 7 years later and were constricted, especially nasally. The I4e was detected at $40^{\circ}$ nasally and $60^{\circ}$ temporally in each eye. The dosage of VGB was reduced. However, her visual field constricted slightly further on two subsequent visual fields to $30^{\circ}$ nasally and $50^{\circ}$ temporally right eye and $35^{\circ}$ nasally and $55^{\circ}$ temporally for the left eye 5 months later. VGB has now been withdrawn. Her visual acuity is $6 / 6$ and her optic discs normal. 


\section{Case 6}

An 18-year-old female with Rasmussen's disease. Her seizures started at 2 years of age and VGB was added to multiple treatment for uncontrolled seizures at 8 years of age. Two surgical procedures were performed to resect diseased frontal and temporal lobes 6 months and 1 year later. Following the second operation there was a left homonymous hemianopia to confrontation and acuity of 6/12 right and 6/18 left. Goldmann visual fields were first achieved 2 years later at 11 years of age, when she complained that she need to move a book up and down to read (Fig. 1a). She was still on VGB therapy. In addition to the left homonymous hemianopia there was constriction of the visual field. Target I4e was detected at $45^{\circ}$ temporally in the right eye and $30^{\circ}$ nasally in the left eye. Her acuity was 6/12 right and left and there was slight optic disc pallor. Seven months later her visual field was constricted further and there was increased pallor of her optic discs. The larger IV4e was detected at $40^{\circ}$ by the right eye and $20^{\circ}$ by the left. VGB was continued for a further 14 months (total of 7 years therapy) and now she has gross constriction of her visual fields with $6 / 5$ acuity and pale optic discs. The visual fields have not improved 3 years later (Fig. 1b). The largest $\mathrm{V} 4 \mathrm{e}$ is detected just past the blind spot at $20^{\circ}$ by the right eye and at $10^{\circ}$ by the left eye.

\section{Case 7}

A 17-year-old male with hypomelanosis of Ito, left hemiparesis and seizures with onset at 6 months of age. At 9 years VGB was added to phenytoin and CBZ. His first eye examination was 8 years 2 months later. His acuity was $6 / 18$ right and $6 / 6$ left. His Goldmann visual fields were constricted to target I4e to $30^{\circ}$ and $40^{\circ}$ nasally and $40^{\circ}$ and $55^{\circ}$ temporally for right and left eyes respectively. With IV4e this enlarged to $60^{\circ}$ and $45^{\circ}$ nasally and $65^{\circ}$ temporally. His optic discs were normal. There has been minimal change, which is not definitely significant, 7 months later. Target I4e was seen at $35^{\circ}$ and $40^{\circ}$ nasally and $40^{\circ}$ and $50^{\circ}$ temporally for right and left eyes respectively and VGB is being withdrawn.

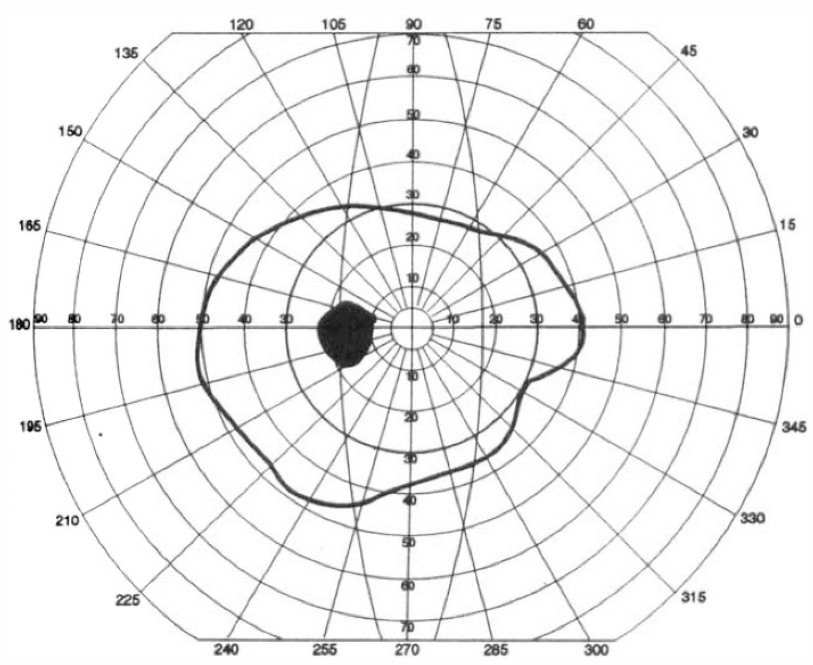

\section{Case 8}

A 10-year-old female with onset of focal seizures at 2 years 8 months of age. She was prescribed VGB for only 2 months 1 year ago in addition to lamotrigine (LMT) and valproate. Her acuity was 6/6 right and 6/9 left with normal optic discs. On Goldmann visual field testing targat $\mathrm{I} 4 \mathrm{e}$ was detected at $50^{\circ}$ nasally by both eyes and $75^{\circ}$ temporally by the right eye and $70^{\circ}$ temporally by the left with an increased blind spot. VGB was discontinued and her current therapy is LMT and topiramate.

\section{Case 9}

A 15-year-old female with onset of seizures at 3 and a half years of age. Three years later she had surgery and radiotherapy for a temporal lobe astrocytoma. VGB was added to multiple therapy at 11 years of age and 2 years and 5 months later her visual fields were constricted, acuity $6 / 5$ each eye and optic discs normal. Six months later her visual field appeared to have constricted since last tested 4 months previously and VGB was stopped. Her optic discs and acuity are still normal yet her visual field has not improved 10 months later. There is a slight suggestion of further deterioration, but her responses are variable. Her detection of target $\mathrm{I} 4 \mathrm{e}$ by the right eye was at $50^{\circ}$ nasally in April 1998 and at $35^{\circ} 14$ months later and also changed from $60^{\circ}$ to $55^{\circ}$ temporally during that time. The response was at $40^{\circ}$ nasally by the left eye on both occasions and deteriorated from $60^{\circ}$ to $50^{\circ}$ temporally (Fig. 2).

\section{Case 10}

A 17-year-old male with onset of seizures at 14 years of age. VGB was added to CBZ in January 1998. Eleven months later his Goldmann visual fields were thought to be full (with targets I2e and V4e), acuity $6 / 6$ for each eye and optic discs normal. However, after 22 months on VGB he had constricted visual fields with a nasal step. He detected target $\mathrm{I} 4 \mathrm{e}$ at $30^{\circ}$ nasally for both eyes and temporally at $60^{\circ}$ for the right and $55^{\circ}$ for the left eye.

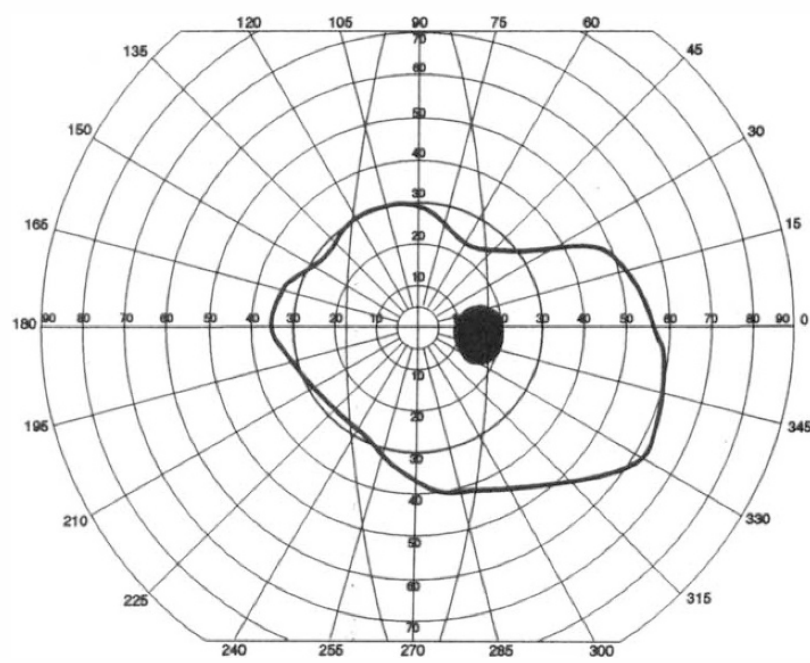

Fig. 2. Case 9. Goldmann perimetry to target 14e, 35 months after starting VGB, showing constriction of the visual fields. 
This visual field constriction was confirmed on a Humphrey visual field analyser. His acuity and optic discs remain normal.

\section{Case 11}

An 8-year-old male with congenital hydrocephalus, porencephalic cyst, right hemiplegia and pale optic discs. Focal seizures started at 3 years 6 months. His acuity was measured on three occasions as 6/9 linear prior to VGB therapy at 5 years of age. Goldmann visual fields were first achieved 38 months later. With target I4e detection was at $30^{\circ}$ nasally for each eye and $40^{\circ}$ and $50^{\circ}$ temporally for right and left eyes respectively. His acuity was $6 / 12$, his optic discs more pale and VGB was withdrawn.

\section{Case 12}

A 15-year-old male with onset of temporal lobe seizures, at 10 years of age, due to a focal lesion thought to be a dysembryoplastic neuro-epithelial tumour. His initial therapy was sodium valproate and CBZ. VGB was commenced in December 1996 in addition to LMT and CBZ, which was started 4 months before. His visual acuity was $6 / 5$, his optic discs normal and he had full visual fields 3 months after starting treatment. He detected target $\mathrm{I} 4 \mathrm{e}$ at $50^{\circ}$ nasally and $75^{\circ}$ temporally in each eye. Now 2 years and 7 months after onset of VGB therapy, at $2 \mathrm{~g}$ per day (recently increased to $3 \mathrm{~g}$ ), his visual acuity and visual fields are still normal.

\section{Case 13}

A 14-year-old female with bilateral hemiplegia and hydrocephalus secondary to intraventricular haemorrhage of prematurity. Her first shunt was at 6 months of age and has been revised twice since for blockage. Her seizures started at 10 years of age. After about 18 months of VGB $500 \mathrm{mg}$ twice a day at 14 years of age she had constricted Goldmann visual fields especially nasally $R>L$, but a blind spot was hard to plot. Target $\mathrm{I} 4 \mathrm{e}$ was detected at $25^{\circ}$ and $30^{\circ}$ nasally and $40^{\circ}$ and $50^{\circ}$ temporally, right and left. Target IV4e was detected at $25^{\circ}$ and $40^{\circ}$ nasally and $70^{\circ}$ and $60^{\circ}$ temporally. There was slight temporal disc pallor. Her visual acuity was $6 / 12$ right (with $+1.00 /-2.00 \times 135^{\circ}$ ) and $6 / 9$ left (with $-1.00 /-1.50 \times 10^{\circ}$ ). It was suggested that VGB should be withdrawn.

\section{Case 14}

A 15-year-old girl with a right parietal dysembryoplastic ectodermal tumour with onset of seizures at 3 years of age. VGB was started together with LMT in March 1996. Her first visual field was performed 11 months later. Target I4e was detected nasally at $40^{\circ}$ and at $50^{\circ}$ temporally. After 3 years and 6 months of VGB she complains of shadows in the side of her vision. On Goldmann visual fields the same I4e target was detected at $35^{\circ}$ nasally and $30^{\circ}$ temporally by her right eye and $30^{\circ}$ nasally and $35^{\circ}$ temporally by her left eye, which is felt to be a significant change. Humphrey visual fields are also grossly constricted yet her visual acuity and ISCEV standard electroretinogram recordings are normal.

In summary 10 of the 14 patients had constriction of their visual fields (cases 1, 2, 5, 6, 7, 9, 10, 11, 13, 14). Four children (cases 5, 9, 10,13) had relative temporal sparing, which has been previously reported in association with VGB. ${ }^{8,10}$ In addition there were 2 cases which were suspicious: case 4 with constriction in addition to the hemianopia associated with her primary pathology and case 8 with an enlarged blind spot in one visual field which is not a typical VGB defect. There was pre-existing visual pathway damage in 4 cases $(4,6,11,13)$ and in 2 of these cases pallor of the optic disc increased with no cause found, but in association with constricted visual fields. However the optic discs were normal in 5 cases (1, $2,5,9,14)$ in spite of visual field constriction. In the majority of cases perimetry was not possible until VGB had been used for many months. The earliest that constriction of visual fields was detected was after 29 months of therapy. There were only 2 patients with normal visual fields: case 3 at 2 years 5 months and case 12 at 2 years 7 months after starting VGB.

Visual acuity was normal in 10 patients, including 8 with constriction of their visual field.

\section{Discussion}

Our study is limited by being a retrospective review. Our patients are limited in their ability to perform perimetry, not only by young age but also, in many cases, by developmental delay. There is the possibility that other medications may contribute to the visual field defects as many of these children have refractory seizures and have had multiple and prolonged therapy. Visual field disorders and retinal changes have also been associated with phenytoin, diazepam and carbamazepine. ${ }^{27}$ In patients who are not alert it is possible that apparent slight constriction of the Goldmann visual fields may be artefactual. Visual field examination was not performed before onset of treatment. In 2 children (cases 4,6 ) the visual field changes are complicated by hemianopia due to the primary disorder or to resection of affected brain. However, we feel that this is an important review as it demonstrates that visual field defects do occur in children receiving VGB.

In 2 children the progressive constriction of the visual field was convincing. In case 6 the visual fields appear to be stable, with 3 years follow-up, once VGB was stopped. However, in case 9 there may have been further slight deterioration over 10 months. Visual fields have been reported to be stable in adults with up to 7 years followup once VGB has been withdrawn. ${ }^{8,17,18}$ In adults no case has deteriorated once VGB was stopped and has rarely been reported to improve: in 4 of 51 cases reported in Australia by September $1998^{28}$ and in one case in a recent report. ${ }^{18}$ In one of our children (case 5) the dosage of VGB was reduced and the visual field appears stable, but there is only 4 months follow-up. Wong et al. ${ }^{14}$ reported 
stable visual fields in an adult 4 years after reduction of the dose of VGB. In the majority there was generalised constriction of the visual fields (cases 1, 2, 5, 6, 7, 9, 10, 11, $13,14)$. This pattern of visual field loss is typical of the visual field loss previously reported in association with VGB. ${ }^{8,10-21}$ The more specific visual defect of an early nasal step was seen in 4 of our children (cases 5, 9, 10 and 13) and has been reported in association with VGB therapy in adults. ${ }^{8,10}$ It has been suggested that as there are no previous reports in the literature of children receiving VGB therapy having visual field constriction that they may not be susceptible. ${ }^{23}$ We suggest that visual field constriction does occur, but possibly only after prolonged therapy. Patients with pre-existing visual pathway damage may be more susceptible. We did not observe the pseudo-cupping of the optic discs that has been reported in adults. ${ }^{19}$

In this series, as in previous reports, normal visual acuity is common even with severe constriction of the visual fields and a normal optic disc appearance can also be falsely reassuring. Confrontation visual field assessment is not sufficient to detect significant visual field defect associated with VGB therapy. Therefore in children who are not able to perform perimetry VGB therapy has a significant risk to be weighed against potential benefit. We believe as suggested in the guidelines proposed previously that VGB should not be used where there is pre-existing visual pathway damage. ${ }^{29}$ VGB is a particularly valuable drug for infantile spasms, although recent evidence suggests that it should not be considered as the first line drug except in cases associated with tuberous sclerosis. ${ }^{30}$ Visual field loss appears to be gradual and rare before 6 months of therapy in adults. Unfortunately this evidence is difficult to obtain in children and even older children are not necessarily comparable to infants with a different seizure disorder. VGB may still play a role in refractory seizures in infancy, but with an as yet unquantifiable risk.

\section{References}

1. Coulter DA. Antiepileptic drug cellular mechanisms of action: where does lamotrigine fit in? J Child Neurol 1997;12(Suppl 1):S2-9.

2. Natsch S, Hekster YA, Keyser A, Deckers CL, Meinardi H, Renier WO. Newer anticonvulsant drugs: role of pharmacology, drug interactions and adverse reactions in drug choice. Drug Safety 1997;17:228-40.

3. Leach PJ, Brodie MJ. Tiagabine. Lancet 1998;351:203-7.

4. Gibson JP, Yarrington JT, Loudy DE, et al. Chronic toxicity studies with vigabatin, a GABA-transaminase inhibitor. Toxicol Pathol 1990;18:225-38.

5. Harding GF. Severe persistent visual field constriction associated with vigabatrin. Benefit:risk ratio must be calculated for individual patients. BMJ 1998;316:232-3.

6. Reynolds EH. Gamma-vinyl GABA (vigabatrin): clinical experience in adult and adolescent patients with intractable epilepsy. Epilepsia 1992;33(Suppl 5);S30-4; discussion S34-5.

7. Faedda MT, Giallonardo AT, Marchetti A, Manfredi M. Terepia con vigabatrin nelle epilessie parziali resistenti. (Vigabatrin therapy for resistant partial epilepsies.) G Neuropsicofarmacol 1993;15:105-8.

8. Eke T, Talbot JF, Lawden MC. Severe persistent visual field constriction associated with Vigabatrin. BMJ 1997;314:180-1.
9. Anon: Does vigabatrin affect the eye? Pharm J 1997;258:120.

10. Mackenzie R, Klistorner A. Severe persistent visual field constriction associated with Vigabatrin: asymptomatic as well as symptomatic defects occur with Vigabatrin [letter]. BMJ 1998;31:233.

11. Wilson EA, Brodie MJ. Severe persistent visual field constriction associated with Vigabatrin. Chronic refractory epilepsy may have a role in causing these unusual lesions. BMJ 1997;314:1693.

12. Blackwell N, Hayllar J, Kelly G. Severe persistent visual field constriction associated with Vigabatrin: patients taking Vigabatrin should have regular VF examination. BMJ 1997;314:1694.

13. Harding G, Wild J, Robertson K, Edson E, Barber C, Lawden $\mathrm{M}$, et al. Electrooculography, EOGs, multi-focal ERGs and VEPs in epileptic patients showing visual field disorders. Electroencephalogr Clin Neurophysiol 1997;103:96.

14. Wong IC, Mawer GE, Sander JW. Severe persistent visual field constriction associated with Vigabatrin: reaction may be dose dependent [letter; comment]. BMJ 1997;314:1693-4.

15. Krauss GL, Johnson MA, Miller NR. Vigabatrin associated retinal cone system dysfunction: electroretinographic and ophthalmological findings. Neurology 1998;50:614-8.

16. Rao GP, Fat FA, Kyle G, Leach JP, et al. Study is needed of visual field defects associated with any long term antiepileptic drug [letter]. BMJ 1998;317:206.

17. Ruether K, Pung T, Kellner U, et al. Electrophysiologic evaluation of a patient with peripheral visual field constriction associated with Vigabatrin [letter]. Arch Ophthalmol 1998;116:817-9.

18. Acheson JF, Wearne MJ, Graham EM, Sanders MD. Vigabatrin-associated visual failure: analysis of 4 cases presenting with major visual field defects. Poster presentation at the Oxford Congress of Ophthalmology, 1999

19. Mackey DA, Craig JE, Gioulekas J, Cooper RL. Vigabatrin associated visual field loss resembling low tension glaucoma. Invest Ophthalmol Vis Sci 1999;40:S63-339.

20. Versino M, Veggiotti P. Reversibility of vigabatrin-induced visual-field defect. Lancet 1999;354:486.

21. Daneshvar H, Racette L, Coupland SG, Kertes PJ, Guberman A. Symptomatic and asymptomatic visual loss in patients taking Vigabatrin. Ophthalmology 1999;106:1792-8.

22. Wilton LV, Stephens MDB, Mann RD. Visual field defect associated with vigabatrin: observational cohort study. BMJ 1999;139:1165-6.

23. Roubertie A, Bellet H, Echenne B. Vigabatrin-associated retinal cone system dysfunction [letter; comment]. Neurology 1998;51:1779-81.

24. Beren R, Currie J, Sandbach J, Plunkett M. Visual field restriction with new anti-epileptic medications [abstract]. European Epilepsy Society, Warsaw, May 1998.

25. Baulac M, Nordmann J-P, Lanoe Y. Severe visual-field constriction and side effects of GABA-mimetic antiepileptic agents. Lancet 1998;352:546.

26. Kalvianen R, Nousiainen I, Mantyjarvi M, Riekkinen Sr PPJ Absence of concentric visual fields in patients with long-term Tiagabine monotherapy. Neurology 1999;52(Suppl 2):P03.118.

27. Harding GFA. Severe persistent visual field constriction associated with Vigabatrin: four possible explanations exist [letter, comment]. BMJ 1997;314:1694.

28. Hoechst Marion Roussel Australia. Guidelines for clinical practise. Visual field constriction and Vigabatrin (Sabril) 1998.

29. Appleton RE. Guidelines may help in prescribing vigabatrin. BMJ 1998;317:1322.

30. Osborne JP, Edwards SW, Hancock E, Lux AL, O'Callaghan $\mathrm{F}$, Johnson $\mathrm{T}$, et al. Infantile spasms and vigabatrin: study will compare effects of drugs [letter]. BMJ 1999;318:56-7. 